\title{
Extensive aortic mediacalcosis: an unusual presentation of primary hyperparathyroidism
}

\author{
Bouomrani $S^{1,2 *}$, Lamloum $I^{1,2}$, Hammami $A^{1,2}$, Mahdhaoui $W^{1,2}$, Naffeti $A^{1,2}$, Mesfar $R^{1,2}$ and Amri $D^{1,2}$ \\ ${ }^{1}$ Department of Internal medicine, Military Hospital of Gabes, Gabes, Tunisia \\ ${ }^{2}$ Sfax Faculty of Medicine, University of Sfax, Sfax, Tunisia
}

\begin{abstract}
Primary hyperparathyroidism (PHPT) is a rare endocrinopathy that is characterized by nonspecific and highly polymorphic clinical manifestations, most often related to hypercalcemia. Vascular manifestations remain exceptional and unusual during this disease and are most often asymptomatic.

We report the original observation of extensive and advanced calcifications of the abdominal aorta (mediacalcosis) causing lumbar pain and revealing PHPT in a 42-year-old man with no pathological medical history.
\end{abstract}

\section{Introduction}

Cardiovascular manifestations remain among the so-called "non-classical" or "nontraditional" complications of primary hyperparathyroidism (PHPT). They are by far dominated by hypertension, left ventricular failure, coronary artery disease, and myocardial and valvular calcifications [1,2].

Characteristic of secondary hyperparathyroidism (in patients with end-stage renal disease on dialysis), arterial calcifications are exceptional and unusual during PHPT [3]. They predominate in small vessels; the involvement of the aorta remains uncommon and not well known by clinicians $[4,5]$.

We report the original observation of symptomatic advanced and extensive mediacalcosis of the abdominal aorta revealing PHPT.

\section{Case report}

A 42-year-old man with no pathological medical history, was explored for mechanical lumbar pain evolving for a month. Somatic examination was without abnormalities. Baseline biology (total blood count, erythrocyte sedimentation rate, C-reactive protein, and creatinine) was within normal limits. The lumbar computed tomography showed no vertebral or disc anomalies. On the other hand, it showed advanced and extensive vascular calcifications of the abdominal aorta (Figures 1 and 2) and the two common iliac arteries (Figure 3).

The patient had no particular cardiovascular risk factors, blood pressure was normal, blood glucose was correct, as well as kidney function and lipid parameters. Subsequent investigations concluded with PHPT: hypercalcemia at $3.22 \mathrm{mmol} / 1,1-84$ parathyroid hormone at $255 \mathrm{ng} / \mathrm{ml}$, and right parathyroid adenoma at cervical computed tomography. The patient was treated with oral hydration, injectable bisphosphonates, and referred to ENT department for surgery of his adenoma.

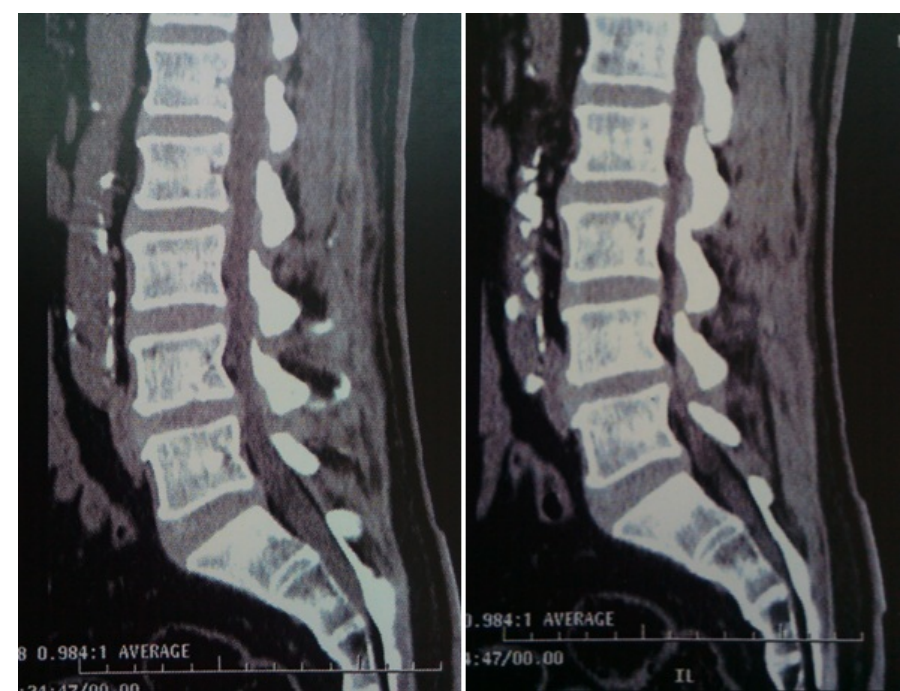

Figure 1. Sagittal lumbar computed tomography/parenchymal window: extensive calcification of the abdominal aorta

\section{Discussion}

Mediacalcosis is exceptional and usually remains asymptomatic during PHPT [6]. The exact prevalence of abdominal aortic calcification in PHPT is unknown, but recent studies have shown a significantly

${ }^{\star}$ Correspondence to: Salem Bouomrani, Department of Internal medicine, Military Hospital of Gabes, Gabes, Tunisia, E-mail: salembouomrani@yahoo.fr

Key words: primary hyperparathyroidism, mediacalcosis, abdominal aorta, ectopic calcification

Received: October 01, 2019; Accepted: October 08, 2019; Published: October 10, 2019 


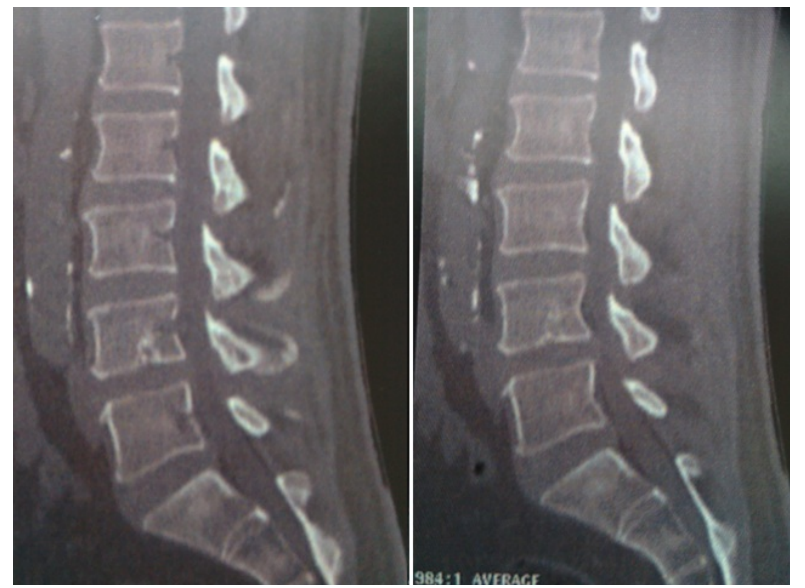

Figure 2. Sagittal lumbar computed tomography/bone window: extensive calcification of the abdominal aorta
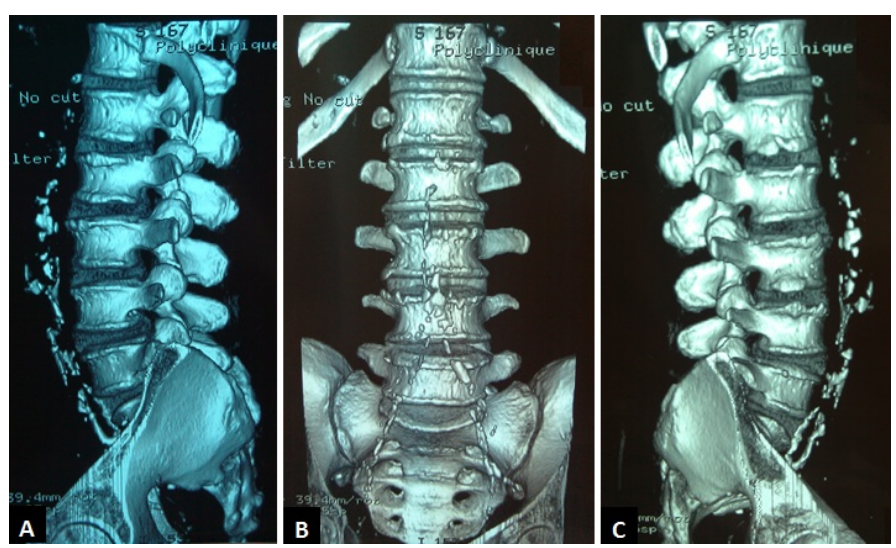

Figure 3. Lumbar computed tomography/Three-dimensional reconstruction/Right lateral (A), front (B), and left lateral (C) views: Extensive and advanced calcifications of the abdominal aorta and common iliac arteries

higher prevalence of abdominal aortic calcification in this disease $(\mathrm{P}=0.03)$ with more extensive and severe calcifications [5].

The exact phatophysiological mechanism of these ectopic vascular calcifications associated with PHPT remains uncertain [4,5]. The only factor significantly associated with their development is the level of parathyroid hormone [5].

These vascular calcifications of PHPT are ubiquitous and contribute significantly to the cardiovascular mortality particularly increased in patients with this disease $[1,2]$.

The differential diagnosis of these calcifications arises with primary mediacalcosis, and secondary mediacalcosis due to diabetes mellitus, chronic renal failure, and secondary hyperparathyroidism [7].

\section{Conclusion}

As rare as it is, PHPT deserves to be evoked in front of any mediacalcosis accidentally discovered on radiological examinations, and that is not proven.

\section{Conflicts of interest}

None.

\section{References}

1. Chiodini I, Cairoli E, Palmieri S, Pepe J, Walker MD (2018) Non classical complications of primary hyperparathyroidism. Best Pract Res Clin Endocrinol Metab 32: 805-820. [Crossref]

2. Walker MD, Rubin M, Silverberg SJ (2013) Nontraditional manifestations of primary hyperparathyroidism. J Clin Densitom 16: 40-7. [Crossref]

3. Roy R, Lee JA (2011) Calciphylaxis due to hyperparathyroidism. Endocr Pract 17 Suppl 1: 54-56. [Crossref]

4. De Francisco AM, Cassidy MJ, Owen JP, Ellis HA, Farndon JR, et al. (1985) Ectopic calcification. The role of parathyroid hormone. Proc Eur Dial Transplant Assoc Eur Ren Assoc 21: 888-94. [Crossref]

5. Pepe J, Diacinti D, Fratini E, Nofroni I, D'Angelo A, et al. (2016) High prevalence of abdominal aortic calcification in patients with primary hyperparathyroidism as evaluated by Kauppila score. Eur J Endocrinol 175: 95-100. [Crossref]

6. Walker MD, Silverberg SJ (2008) Cardiovascular aspects of primary hyperparathyroidism. J Endocrinol Invest 31: 925-31. [Crossref]

7. Lanzer P (1998) [Media calcinosis from the viewpoint of the cardiologist]. Z Kardiol 87: 928-938. [Crossref]

Copyright: (C2019 Bouomrani S. This is an open-access article distributed under the terms of the Creative Commons Attribution License, which permits unrestricted use, distribution, and reproduction in any medium, provided the original author and source are credited. 